\title{
PRINCIPIOS ÉTICOS PARA LOS CIBERPERIODISTAS EN EL MANEJO DE LAS REDES SOCIALES
}

\section{Ethical principles for the Cyberjournalist in the management of the social networks}

\author{
AUTORA: NAVARRO ZAMORA, Lizy \\ Profesor Investigador - Universidad Autónoma de San Luis Potosí - Mexico
}

lizy@uaslp.mx

\begin{abstract}
Resumen
Se realizó un estudio sobre los Manuales de Ética que los cibermedios utilizan como guía para los ciberperiodistas al momento que estos manejan las redes sociales, tanto de su cibermedio como las privadas. En el estudio primero se efectuó una búsqueda de los manuales existentes tanto en Estados Unidos, como en Europa y América Latina, se revisó el discurso propuesto en cada uno de ellos, posteriormente se estudiaron los principios constantes entre los diferentes manuales tanto en español como en idioma inglés, después se realizó un análisis de contenido de las redes sociales con cada una de las variables relacionadas a lo recomendable hasta la actualidad. Como resultados tenemos que los ciberperiodistas en América Latina emplean de manera incorrecta las redes sociales personales, frente a los ciberperiodistas de Europa y Estados Unidos, ello depende por supuesto del desarrollo de los manuales de estilo, del contexto de podercorrupción de los cibermedios. La máxima ética es que las Redes Sociales, su expresión en espacios digitales, se convierten en una extensión del quehacer profesional de los ciberperiodistas. Este es un elemento fundamental de formación para los estudiantes de comunicación, de periodismo y periodistas en activo, sobre todo en lo que se refiere a la ética.
\end{abstract}

\section{Palabras clave}

Ciberperiodista, ética, redes sociales

\begin{abstract}
This study was realized about the Ethics Manuals wich are used by the cybermedia as a guide for the cyberjournalists when they use social network in the cybermedia and the private role. In the study, first, was realized a research of the manuals existents in the United States, Europe and Latin America, revised proposed in each speech. After the constants principles were reviewed between the diferents manuals in spanish and in english. Later, was realized a content analysis about social media with each one of the related variables applicables today. As result we have that cyberjournalists in Latin America use the personal social network incorrectly toward the cyberjournalists from United States and Europe, it depends, of course, of the style manuals development and the power-corruption context in the cybermedia. We conclude that Social Media, it expression in digital spaces is transformed in an extension of their professional role. This is a fundamental element of training for students of communication, journalism and journalists active.
\end{abstract}

\section{Key words}

Cyberjournalist, ethics, social networks

\section{Justificación e Introducción. El Porqué de la Importancia de las Redes Sociales para el Ciberperiodista}

El presente trabajo es el resultado de un proyecto que inició en 1997, un Observatorio de los Cibermedios, sobre el desarrollo que los medios digitales han tenido desde el año de 1994 en que se instaló el primer medio 'The Mercury News'. Al consolidarse el ciberperiodismo a través de Internet, con el crecimiento exponencial de la red, después de la transformación e intervención comunicativa de las redes sociales, es importante reflexionar e investigar en torno a temas relevantes como la relación entre la ética y el uso de las redes sociales.

Aún cuando la ética en el ejercicio del ciberperiodista depende parcialmente de la ética del propio 
cibermedio, las TIC's han brindado otros espacios que han transformado la comunicación a través de las redes sociales. Aquí cabe una pregunta: ¿cuándo dejamos de ser periodistas? El trabajo del ciberperiodista es muy importante en la nueva era comunicativa: es el responsable de jerarquizar, organizar y presentar la información que le interesa a cada persona, según sus expectativas.

Parafraseando al doctor José Luis Martínez Albertos en su libro 'El Ocaso del Periodismo', los periodistas deben trabajar la noticia rigurosamente verificada, contextualizar los hechos dentro de un marco de referencias actuales, históricas y de proyección de futuro y distinguir entre hechos y opiniones para no engañar, para ser honrados y honestos respecto a los receptores.

La calidad de la información sólo puede ser respaldada por profesionales del contenido: los periodistas. Según hemos considerado a lo largo de la historia de esta profesión: "El periodista tiene que seguir siendo también en el ámbito digital un gatekee-per, filtro de las informaciones y rumores que se producen, $\mathrm{y}$ advocate, mantener una posición clara y limpia respecto a los acontecimientos de los que informa." (Díaz y Meso Ayerdi, 1999: 120).

Los elementos del ciberperiodista son la sinceridad y la conciencia. Por ello deben rechazar remuneración ilícita, ya sea directa o indirectamente, promover intereses al bien común y los derechos humanos, resistirse a las presiones de todo poder, favorecer el derecho a la información de los ciudadanos, respetar a las personas en su vida privada y dignidad. Todos estos son elementos fundamentales para la construcción de la ética en el ciberperiodismo.

Las redes sociales son un tema de investigación, igual que las redes sociales en su correlación con el ciberperiodismo que incluye tres ámbitos diferentes: al cibermedio, al usuario y al ciberperiodista. ¿El ciberperiodista es uno en los espacios digitales del medio y es otro en los personales?

Esto ha llevado al desarrollo de cuestionamientos y reflexiones, en torno a dicha extensión. La vida privada y pública no podemos separarla, no somos dos entes distintos, al contrario, el ser humano se construye a partir de sus diversas realidades, desde la complejidad del ser y esa construcción se trasmina en todos los espacios. Otro aspecto importante a considerar es cómo utilizar las redes sociales para cumplir con las máximas del periodismo que es el derecho a la información y a la opinión de los ciudadanos.

El número impreciso de miles de millones de páginas web con información de actualidad -algunas de ellas construidas por empresas de prestigio periodístico, pero la mayoría con contenidos imprecisos-, invita a mirar en torno a un elemento fundamental del periodismo: la Ética del Ciberperiodismo.

\section{Objetivos}

El objetivo principal fue conocer el uso de las redes sociales por los ciberperiodistas y si coinciden con los Manuales de Estilo en torno al manejo de las redes sociales del trabajo y las personales.

\section{Metodología de la Investigación}

Se realizó primero una búsqueda de los Manuales de Estilo existentes en los cuales se considera el uso y manejo de las redes sociales por los cibermedios, posteriormente se revisaron los principios constantes entre los diferentes manuales tanto en español como en idioma inglés. Finalmente se analizaron las constantes de aplicación en un grupo aleatorio de ciberperiodistas. Para ello se compararon los lineamientos con las redes sociales de los ciberperiodistas. 


\section{Marco Teórico: Un Acercamiento al Tema. La Interactividad.}

Cuando hablamos de un medio de comunicación nos centramos en los procesos comunicativos, para que el círculo de la comunicación se cierre es necesaria la retroalimentación, Internet la tiene y se denomina Interactividad. De hecho se habla precisamente del éxito de la red por las amplias posibilidades que ofrece el medio para comunicarse con el receptor.

La retroalimentación es casi inmediata. Todo depende del servidor que se tenga para que la opinión, información o respuesta llegue a quien nosotros deseemos. Se presenta una bidirección donde el emisor y el receptor se encuentran en el mismo plano. Así, el tradicional esquema de emisor-canal-receptor se transforma y el receptor termina siendo el emisor.

Los canales se multiplican y los emisores y receptores se confunden e intercambian sus papeles. La característica clave de Internet, la comunicación individual y en grupo: de uno hacia uno; de uno hacia muchos, y viceversa. Este elemento ha tenido una evolución. En 1995 pocos medios y periodistas lograban la interactividad directamente con los receptores del mensaje a través del correo electrónico; para el año 2000 era una constante de los ciberperiodistas la comunicación directa. De hecho se abrió un espacio laboral para el comunicólogo, el lector de correos que apoyaba al ciberperiodista para dar respuesta y lograr la comunicación. Este gráfico que continúa es un ejemplo de dicha interactividad.

Gráfico 1: La interactividad permite, al menos en potencia, una verdadera comunicación con el cibermedio

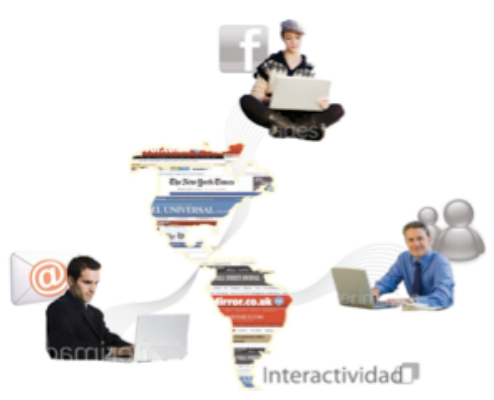

Fuente: Elaboración propia
Hoy los medios más desarrollados en el ciberperiodismo han pasado a una siguiente fase de retroceso y tienen una mínima interactividad con el emisor del mensaje. La interactividad con los periodistas se daba en el año 2000 , en cada unidad redaccional aparecía el correo electrónico del autor, hoy los correos de los periodistas están escondidos y se requiere de una búsqueda minuciosa para encontrarlos. Por supuesto que el ciberusuario no utilizará ese tiempo para comunicarse con ellos. No olvidemos que el agobio del tiempo es uno de los elementos que más identifica esta posmodernidad.

La interactividad con el medio no es una interactividad real, en apariencia el medio permite que el usuario se comunique. Le llamaría el grito en la montaña, el usuario habla, pero sólo él se escucha. De hecho es la interactividad que prevalece y aquí algunos medios le llaman como el Reforma.com: Comentarios al editor.

El periodismo y el ciberperiodismo se construyen con base en pilares esenciales como la precisión, la veracidad, la independencia a intereses de grupos de poder. Las redes sociales expanden nuestros alcances de Interactividad, que nuestros alcances periodísticos no se quedan en la página de los cibermedios, sino que van más allá a través de nuestra comunicación que hagamos en nuestros espacios.

Pongamos en comparación a un profesor de educación básica, sabemos que su jornada laboral tiene un tiempo determinado, de 5 o de 8 horas, pero su congruencia entre lo que dice y hace se extiende ampliamente hacia todos sus espacios, no sólo en comunidades pequeñas, sino en las grandes ciudades, en los espacios físicos como en los digitales.

Como lo menciona Omar Raúl Martínez en su texto 'Repensar el Periodismo':

La ética periodística es el conjunto de valores o principios de actuación deseables que hace suyos un informador para encarnar los objetivos que a su entender debiera cumplir el periodismo que él valora 
y respalda. Tales valores son el apego a la veracidad, la búsqueda de independencia, la asunción de responsabilidad, el compromiso de integridad profesional, y el afán de servicio a la comunidad. (2011: 151)

Ya han pasado 21 años de los primeros cibermedios en Internet, los ciberperiodistas ya se están formando en las Facultades profesionalmente y a través de cursos específicos en las ciberedacciones. Se ubica a la ética de los cibermedios como lo menciona el 'Conjunto de Guías Éticas para hacer Periodismo en la Web', publicado en la Knight Center: "Los recursos limitados, la novedad de la publicación on line o la carencia de protocolos no pueden llegar a ser una excusa para un trabajo de mala calidad y que cause daño.” (2011: 51).

Los principios éticos deben aplicarse a través de todas las plataformas existentes y las que existirán. El deber periodístico conserva su esencia tanto en los espacios digitales como en los analógicos: cumplir con el derecho a la información de los ciudadanos y los hechos son sagrados y las opiniones son libres.

Ningún medio tradicional analógico logra la interactividad, sin embargo Internet lo permite, por supuesto en potencia. Es posible conocer con bastante exactitud cuáles son las secciones o periodistas favoritos del usuario. El único medio que tiene el periódico impreso para conocer la opinión de los lectores son las cartas que se reciben y cuando el medio de comunicación, ya sea el impreso o los audiovisuales, necesita conocer la opinión de los receptores, se encarga una encuesta. "A partir de la posibilidad de la navegación horizontal y de la interactividad directa con los usuarios, la información puede alcanzar un valor añadido: la relación automática entre informaciones.” (López, 2007: 48)
Actualmente, tanto la prensa digital de forma especifica como los espacios virtuales de la red de Internet, en general, ofrecen a los ciudadanos múltiples posibilidades de interacción. Que estos encuentros constituyan auténticas experiencias de participación democrática en la vida social... (Molina, 2008: p. 176).

Dicha interactividad es muy importante porque trasciende la transmisión de información para construirse la comunicación. Sin embargo la interactividad fue algo que se motivó al principio de los cibermedios, hoy se realiza a través de las redes sociales que comparte el emisor con el receptor; es decir el ciberperiodista con el llamado amigo de la red social, el usuario.

Existen entonces grandes retos para la empresa pero también para el ciberperiodista:

Pero frente al limitado modelo interactivo de los medios tradicionales este nivel de participación es un verdadero reto, no solo por las exigencias tecnológicas que su implantación demanda, sino especialmente por el cambio profundo al que se ve sometida la industria periodística. (Llano, 2005: 10).

Cómo lo mencionan Marisol Gómez Aguilar, Sergio Roses y Pedro Farias Batlle: Las redes sociales se han convertido en el principal medio de comunicación on line, otorgándoles a los usuarios un papel activo, donde pueden aportar contenidos y conocimientos. Dentro de la Web 2.0 y a medida que ha ido aumentando la creación de los sitios de redes sociales, se observa una mayor variedad de éstas con diferentes objetivos y funciones. De esta manera se encuentran con redes sociales generalistas o de ocio, redes verticales y redes sociales profesionales. En cuanto a éstas últimas, tienen como objeto principal fomentar, incentivar y aumentar las relaciones entre profesionales, tanto de un mismo sector, como de sectores distintos. (2013: 35).

\section{Las Redes Sociales}

El correo electrónico continúa siendo la principal actividad del usuario de Internet. Algunas de las redes sociales más empleadas por los cibermedios y los ciberperiodistas son: Facebook, Twitter, Digg, My Space, Save, Delicious, Resqui, Technorati, Mixx, Meneame. De hecho cada medio puede crear 
su propia red social como el caso de 'El País.com' quien tienen la red Eskup. Países como China tiene sus propias redes sociales porque es una forma de control político del gobierno, o como lo han revelado fuentes fidedignas, el servicio secreto de Estados Unidos vigila a los ciudadanos a través de estos medios.

El impacto de las Nuevas Tecnologías de la Información y Comunicación ha tenido diferentes momentos de transformación. El surgimiento de las redes sociales ha impactado en todos los ámbitos de las Convergencias Digitales y del Nuevo Paradigma. Es significativa la necesidad que tiene el ciberperiodismo, por tener mayor cantidad de usuarios, sobre todo incorporar a la población joven.

Por ello se han adaptado estrategias de vinculación entre los cibermedios y las redes sociales. En ello el espacio encuentra los canales multisalida y con ello se genera el rastreo de impacto de la noticia en otros medios. No existen datos precisos de cuántos ciberusuarios llegan a la información periodística a través de las redes sociales y no de los propios cibermedios. Las herramientas para compartir contenidos son ligas de sitios que ofrecen a los usuarios de Internet un método para almacenar, organizar, buscar, administrar y compartir las páginas favoritas de internet.

Tabla 1: Algunos usos ciberperiodísticos de las redes sociales.

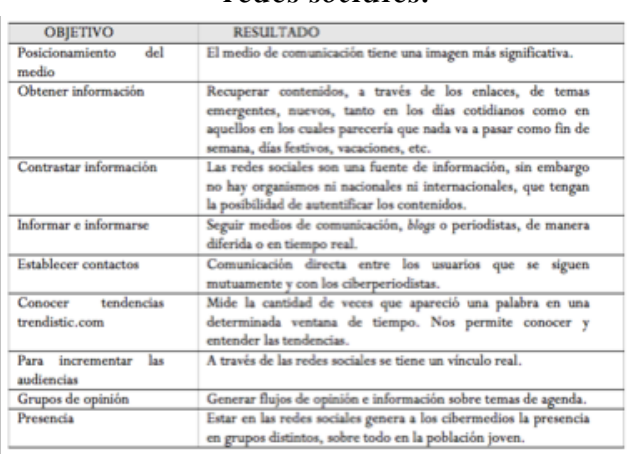

Fuente: Elaboración propia

Las redes sociales como Facebook y Twitter cada día se convierten en un mayor lugar de intercambio de información, de ideas, opiniones, con tan solo un toque de pantalla a través de una computadora de escritorio, portátil, una tableta y teléfonos que llamamos inteligentes (smartphone), con lo cual se puede hacer una efectiva comunicación. Existe una diversidad de redes sociales, pero Facebook hizo una transformación radical a la comunicación, con la mayor cantidad de usuarios esta red llegó a un promedio de 1450 millones de usuarios. Desde su creación en el 2004, rompió todas las barreras geográficas y se introdujo en diferentes culturas físicas y laborales.

Facebook se volvió para los periodistas un espacio donde se pueden retomar tips para realizar las investigaciones de los diferentes cibergéneros, una plataforma para conectar a personas relacionados a casos que estén investigando y hasta una medición social como la guerra en Siria, las elecciones presidenciales de Estados Unidos, el narcotráfico en América Latina.

Una plataforma que generó una excelente opción para mostrar contenido creado en portales de noticias ya que la información puede convertirse en algo viral con la exposición que se le de mediante las diferentes acciones que se permiten. Like (Me gusta) o share (Compartir) son estas los detonantes para un mayor impacto y distribución de la información. En Facebook los usuarios crean perfiles personales, grupos (privados o abiertos) y páginas de likes. Esta es la parte donde el ciberperiodista debe seguir principios éticos para sus uso y manejo, no es un ciudadano común, es en su comunicación una extensión.

La red social Twitter le da un significado y sobre todo para periodistas que viven de informar acontecimientos minuto a minuto. El principal atractivo de la red social, es que limita sus publicaciones nombradas tuits tan solo a 140 caracteres para su inmediatez, esto parecido a como iniciaron las noticias en el siglo XIX y se transmitían por el telégrafo, como también las noticias a través del teletexto o del celular. La rapidez con que se transmiten supera por mucho todo el proceso de publicación de cualquier portal de Internet, de un medio impreso y de un comercial de televisión. 
Ha llegado a ser comparada esta red con la radio por la intensidad de su frecuencia y el gran impacto que tiene. Todos los usuarios de Twitter deben tener un conocimiento del vocabulario que pertenece a esta red. Un ejemplo, DM es un direct message o mensaje directo y se realiza mediante un mensaje en comunicación privada con uno de los usuarios, ya que todos los twits son públicos. Otro término muy común es el retweet o RT que es compartir un mensaje ya publicado en Twitter por otro usuario.

Para mencionar otra cuenta se etiqueta por medio del arroba (@) antes del nombre de usuario y aparece un hipervínculo hacia el perfil nombrado. También se encuentra otra forma de generar etiquetas llamadas hashtags, que son términos o palabras clave que acompañadas del signo de número (\#) desarrollan una especie de filtro que agrupa toda la información vinculada a un tema en específico. De esta manera se simplifica la búsqueda de información en los usuarios de redes sociales y administradores de las comunidades en Internet. Para los medios de comunicación este filtro genera tendencias para encontrar los temas más populares entre la comunidad, llamados Trending topics (TT).

Hablando del caso particular de Japón, se transmitió twit a twit la llegada del tsunami al país, lo que mantuvo alerta a las autoridades y a los que estaban de residentes para el desalojo del área afectada. Las instituciones gubernamentales lanzaron sus números de contacto a través de Twitter, incluso la Cruz Roja recurrió a este espacio para recaudar fondos y ayuda para los damnificados.

En Youtube las imágenes en movimiento se expanden rápidamente en las redes sociales, lo que ha logrado que los medios de comunicación masivos cuenten con información y material del suceso para reproducirlos y a su vez aceptando que no estaban en la escena de la noticia en el momento, pero los ciudadanos si.

Este portal publica videos creados por usuarios comunes, fotoperiodistas, empresas y medios de comunicación, entre otros. Generando un espacio público para la creación y divulgación de cualquier contenido audiovisual sin necesidad de una plataforma como un canal de televisión.

En la red Instagram, a diferencia de las anteriores, esta red social se genera únicamente por medio de una aplicación móvil es sorprendente como puede transformarse en un espacio social con tan solo compartir contenido fotográfico generado por los usuarios. Es una herramienta para celulares inteligentes que permite a sus usuarios la publicación de fotos con un mini editor que les proporciona filtros y algunos otros efectos especiales. Las imágenes publicadas son vistas y likeadas por sus seguidores, quienes pueden comentar o presionar en "me gusta" para demostrar mediante esta señal del agrado o gusto por la publicación.

LinkedIn es exclusivamente una red social para profesionales. El principal propósito es reunir a trabajadores de diversos campos en un mismo lugar en Internet. Hay muchos beneficios para los periodistas que frecuentan esta red social, pueden conseguir profesionales para entrevistar, buscar colegas que puedan informar desde cualquier parte del mundo y encontrar información de protagonistas de noticias. La red social es básicamente un currículum en Internet por lo que detalles personales y aceptación de solicitudes de amistad deben tomarse con precaución. Además de que tus mismos contactos pueden calificar tus aptitudes y habilidades en las que se desarrollen.

\section{Resultados y Discusión. Principales Manuales y Lineamientos de las Redes Sociales}

Uno de los textos que ha reunido a la mayoría de los Manuales de Estilo en el Manejo de las Redes Sociales es el de 'Mejores Prácticas para Medios Sociales. Guías Útiles para las Organizaciones
Periodísticas de la American Society of News Editors' (ASNE) (2011), Estados Unidos.

Una de las principales dudas es si las normas éticas, manuales de estilo para trabajar en un cibermedio 
son similares o iguales a las que se manejan en un medio de comunicación analógico, lo cierto es que sí, finalmente los espacios de comunicación de cualquier naturaleza requieren a un ciberperiodista o periodista consciente de la importancia que tiene en los medios de comunicación.

Los reporteros deberían actuar 'on line' de la misma forma en que lo hacen en persona. No deberían decir nada que no desearían ver en la primera página de su periódico, y no deberían publicar nada que los avergonzaría personal y profesionalmente o a su organización. Esto parece de sentido común, pero para muchos periodistas no es obvio. (ASNE, 2011: 5)

Existe un imaginario en la vida profesional, sobre todo de los más jóvenes en el ámbito del periodista en el cual se piensa que los actos privados están completamente separados de los actos públicos, al igual que el discurso; esto es completamente falso, como seres humanos integrales todos nuestros espacios se convierten en uno solo.

Asuma que todo lo que escribe 'on line' llegará a ser público. Eso es cierto, incluso si está en una cuenta que no está explícitamente conectada con su empleador. Los parámetros de privacidad están constantemente cambiando, y lo que usted escribe un día detrás de las paredes de alguien, al día siguiente podría estar al alcance del público. $\mathrm{O}$, más probablemente, podrían ser filtrados por un antagonista. (ASNE, 2011: 6)

Los ciberperiodistas en muchas ocasiones olvidamos la diferencia entre los espacios públicos y privados, también se siente una popularidad que en momentos en lugar de emisor, el ciberperiodista se quiere convertir en mensaje de la comunicación. Esto provoca un comportamiento equivocado.

Use los medios sociales para relacionarse con los lectores, pero profesionalmente. Un valor importante de estas redes es que ofrecen la oportunidad de relacionarse con los lectores y las fuentes en formas que anteriormente no eran posibles. Los reporteros y editores pueden ver qué está generando alboroto, recolectar información en tiempo real durante desastres y mejorar los esfuerzos del periodismo comunitario. (ASNE,2011: 7)
El ciberperiodista tiene una ideología, una preferencia religiosa o no religiosa, sin embargo esto no debe de interferir con los cibergéneros informativos e interpretativos. Por supuesto que puede presentar su postura, pero siempre que sea en los espacios de opinión y que el usuario no confunda una cibernoticia con una ciberopinión.

Evite la aparición de conflictos de intereses en el área que cubre ofreciendo claras limitaciones de responsabilidad. Los reporteros deberían aclarar que retuitear o enlazar elementos que podrían interesar a sus seguidores no es un respaldo al contenido... Para un periodista, eso no expresa apoyo a lo que ellos tenían que decir. Para los lectores o extraños, puede no ser tan claro. Esto puede ser aclarado modificando el trino o con una simple aclaración, tal como.. Retuitear no es igual a avalar. (ASNE, 2011: 9)

Por otra parte, el ciberperiodismo también tiene un proceso de edición, pero sobre todo de supervisión y verificación de la información, los cibereditores no pueden publicar algo o permitir estar a la mano de todo lo que tenga acceso a la red si antes no se ha contextualizado y verificado. Debido a lo anterior mucho ciberperiodistas prefieren publicar primero en sus redes sociales, lo cual no es recomendable, en el ámbito profesional, sobre todo en la construcción de comunicación es importante que alguien supervise los contenidos.

Publique las noticias de última hora (exclusivas) en su sitio web, no en Twitter. Los medios sociales pueden llegar a ser un succionador de tiempo, distrayendo a los reporteros de conducir la reportería tradicional o ejecutar los deberes de su trabajo. En un clima periodístico que valora la velocidad, hay grandes tentaciones e incentivos agregados para publicar las noticias de última hora en Twitter o Facebook en lugar de esperar para moverlo en el conducto editorial. (ASNE, 2011:8)

La inmediatez que es una característica del ciberperiodismo, en muchas ocasiones pareciera que presiona al ciberperiodista a consultar información que no ha sido comprobada. En muchas ocasiones el termómetro solamente lo mide por el número de menciones que se han dado, por el número de veces que se han compartido, por el número de me gusta 
en la red, es decir la popularidad que se tiene.

No toda la información en los sitios de redes sociales es creada igual. La naturaleza democrática de la web significa mucho ruido inexacto. Lo que hace el papel de filtro de la organización periodística más importante que nunca. Algunos reporteros han estado demasiado ansiosos de abalanzarse sobre cualquier cosa que ven 'on line', pero ser un buen 'guardameta' significa autenticar cuidadosamente cualquier información encontrada en Twitter o en Facebook. Al igual que un dato recibido de una fuente por teléfono, es punto de inicio para más reportería. La vieja regla de usar dos fuentes confiables todavía se aplica.

(ASNE, 2011:11)

Existen recomendaciones específicas de los Manuales de Estilo de algunos medios de comunicación en el siglo XX, en todos los principios una de la recomendaciones esenciales es precisamente lo que se define a continuación que es la identificación plena de uno como ciberperiodista, no trabajar bajo la figura del anonimato, justificando riesgos.

Siempre identifíquese como un periodista. El anonimato no es más aceptable en foros 'on line' de lo que es en un evento político u otro escenario tradicional de información. Uno puede permanecer en sitios públicos 'on line', pero no debería hacerse pasar por otra persona para obtener acceso a material que no es público. Cuando piden a alguien información, especialmente si planean publicarla, se espera que los reporteros se identifiquen abiertamente. (ASNE, 2011: 13)

Otro de los puntos esenciales es la recomendación de corregir los errores que se cometan en la información y en la transmisión de opiniones. En la comunicación siempre publicamos los errores y es evidente que nuestros usuarios en algún momento los conocerán.

Sea transparente y corrija errores donde los cometa. Admita rápidamente cuando esté equivocado. Los errores ocurren, lo mismos que en el impreso. Pero existen tentaciones en los medios sociales que los pueden complicar. De acuerdo con la idea de que los mismos estándares que se aplican a la información tradicional rigen para la información hecha en Internet. Los periodistas deben entender que son respon- sables de ser transparentes y abiertos sobre sus errores... (ASNE, 2011: 15)

Es importante que la confidencialidad en las decisiones de los editores se conserve, no por cuestiones de corrupción, sino al contrario por el sentido que las decisiones también se toman por principios éticos, por ejemplo si se va a dar una información de un posible atentado, en las salas de la ciberedacción se debe de decidir cuál es el mejor beneficio si comunicarlo o no hacerlo.

Mantenga confidencialidad sobre las deliberaciones internas. Los medios sociales pueden amenazar la integridad del proceso editorial. Las decisiones editoriales minuciosas eran tradicionalmente hechas a puerta cerrada, y las personas externas solo veían el producto final. Twitter y Facebook ofrecen ventanas a la cobertura que hacen poner nerviosos a algunos editores. Fuentes escriben sus impresiones sobre las entrevistas que les hicieron. Algunos reporteros tuitean sobre la reportería y el proceso de edición. (ASNE, 2011: 16)

Por otra parte en Latinoamérica se han desarrollado apartados importantes en torno al ciberperiodismo como en el 'Código de Ética Periodística de la Asociación de la Prensa Uruguaya', esto en el apartado VII. Periodismo digital y redes sociales. Una de las principales observaciones es la de que los ciberperiodistas deben de actuar con principios éticos similares que se aplican en los medios analógicos, así como respetar los derechos de autor, cuestión que hasta el momento es uno de los principales problemas que se tienen.

45. Los periodistas harán uso de las redes sociales y las nuevas tecnologías en general con atención a las mismas recomendaciones de ética profesional enunciadas en el presente código respecto a los medios tradicionales.

46. Evitarán el uso de imágenes extraídas de manera inconsulta de redes sociales ya que es deshonesto y violenta los derechos de los propietarios de los materiales. En caso de que se considere periodísticamente relevante su publicación, se recomienda tomar contacto con la persona que la publicó, verificar la información publicada, confirmar que la imagen es real y pedir autorización para 
publicar. (Asociación de la Prensa Uruguaya, 2012: 9)

Otra de las principales cuestiones es el respeto a los derechos de autor de información, imágenes y contenido tomado de otros espacios digitales, así como la identificación de profesionistas como tal utilizando nombres reales sin engañar a las fuentes para obtener información.

47. En caso de reproducir contenidos tomados de redes sociales los periodistas deben proceder con el mismo rigor que aplican con el resto de las fuentes de información.

48. Los periodistas procurarán evitar la edición de blogs personales o perfiles en redes sociales falseando $\mathrm{u}$ ocultando su identidad. Se recomienda la identificación con su nombre verdadero y aclarar si los comentarios contenidos en la publicación se realizan a título personal o involucran al medio en el que trabaja. (Asociación de la Prensa Uruguaya, 2012: 9)

Se recomienda no reaccionar de manera negativa, con molestia y con intención de dañar a otro, a través de los espacios digitales que maneja el ciberperiodista.

49. Se recomienda no responder a insultos o provocaciones en foros virtuales o contestar de manera violenta o denigrante a mensajes que cuestionen el desempeño del periodista o al medio en el que trabaja, a fin de preservar su prestigio profesional.

50. Los periodistas deben promover la permanente capacitación en Nuevas Tecnologías de la Información, a fin de lograr una mejor interacción con las audiencias y al mismo tiempo una discusión sobre los dilemas éticos de su utilización. (Asociación de la Prensa Uruguaya, 2012: 9)

Otro de los espacios que ha sido referente en el periodismo es la agencia EFE como el 'Manual de Estilo Redes Sociales EFE'. Aquí una de las cuestiones básicas es el uso de cuentas oficiales que permitan la identificación oficial de los ciberperiodistas.

Cuentas Profesionales: La Agencia EFE promoverá que sus empleados -tanto del ámbito informativo como de gestión- dispongan de cuentas profesionales ligadas a áreas de su especialidad, con el fin, entre otros, de facilitar el acceso a fuentes informativas que utilicen dichos canales... En el caso de Twitter, todas las cuentas profesionales utilizarán el registro “@EFEnombreapellido” o similar, y sus titulares se identificarán en el perfil en función del área en la que trabajan... (Agencia EFE, 2011).

Un segundo punto esencial que destaca el Manual de Estilo es la responsabilidad que tienen en el comunicar en los contenidos de sus redes sociales, las cuales no dependen del cibermedio, sino de los intereses personales del ciberperiodista.

2. Cuentas Personales. La Agencia EFE no se responsabiliza en ningún caso del contenido de cuentas, blogs o perfiles en redes sociales que no hayan sido autorizadas previamente por la Dirección...EFE subraya también que es especialmente recomendable ser muy cuidadoso a la hora de realizar comentarios que puedan revelar apoyo o filiación de cualquier tipo, en especial en el caso de los periodistas. (Agencia EFE, 2011)

Por otra parte, se encuentran los lineamientos que tiene 'The Wahington Post' en torno al manejo de las redes sociales, este cibermedio como uno de los más importante en el mundo y referente para los estudiantes y para quienes ejercemos el periodismo y el ciberperiodismo:

Las redes sociales son medios de comunicación, y una parte de nuestras vidas diarias. Pueden ser valiosas herramientas para recolectar y diseminar información. También crean algunos peligros potenciales que necesitamos reconocer. Cuando usan herramientas de redes sociales para hacer periodismo o para nuestras vidas personales, debemos recordar que los periodistas de 'The Washington Post' son siempre periodistas de 'The Washington Post'. Las siguientes directrices aplican a todos los periodistas de 'The Washington Post', sin limitación por el contenido de sus tareas.

Este cibermedio solicita a sus trabajadores se identifiquen como tal a través de sus redes sociales sin ocultar o variar los nombres. Es decir el ciberperiodista debe enfrentar las consecuencias de asumir una postura, pero sobre todo de hacer valer el derecho a la libertad de expresión. 
Usando herramientas de redes sociales para reportear. Al usar redes sociales tales como Facebook, LinkedIn, My Space o Twitter para reportear, debemos proteger nuestra integridad profesional. Los periodistas de 'The Washington Post' deberían identificarse a sí mismos como tales. Debemos ser exactos en nuestra reportería y transparentes sobre nuestras intenciones cuando participamos. Debemos ser concisos y claros cuando describimos quiénes somos y qué información buscamos. (ASNE, 2011: 44)

A pesar de la aparición de los cibermedios, de los espacios digitales significativos, este cibermedio aboga por un principio básico de los ciberperiodistas y periodistas que es el de que los hechos son sagrados y las opiniones son libres, no confundir ambos puntos.

Cuando se usan estas redes, nada de lo que hagamos debe poner en duda la imparcialidad de nuestro juicio noticioso. Nunca abandonamos las directivas que gobiernan la separación de noticias de la opinión, la importancia del hecho y la objetividad, el uso apropiado del lenguaje y el tono y otros sellos de nuestra marca de periodismo.

Nuestras huellas de información online se reflejan en nuestras reputaciones profesionales y de aquellos de 'The Washington Post'. Asegúrese de que su patrón de uso no sugiere, por ejemplo, que usted solo está interesado en gente con un punto de vista particular sobre un tema. (ASNE, 2011: 44)

Este cibermedio ubica uno de los puntos esenciales en la comunicación del ciberperiodista y de su desarrollo profesional y personal, es de los pocos que afirman, que no se deben de combinar las cuestiones profesionales frente a las personales, sino que al contrario, el ser humano es uno solo.

Todos los periodistas de 'The Washington Post' renuncian a algunos de los privilegios personales de los ciudadanos privados. Los periodistas del Post deben reconocer que cualquier contenido asociado con ellos en una red social online es, para propósitos prácticos, el equivalente de lo que aparece debajo de sus créditos (nombres) en el periódico o en un sitio web.

Debería asumirse que todo lo que usted hace en redes sociales está públicamente disponible para cualquiera, incluso si usted ha creado una cuenta privada. (ASNE, 2011: 44)

También se manifiesta un punto básico que es el de no recibir regalos, apoyos u otros beneficios con el afán de no contaminar los principios básicos de los ciberperiodistas.

Los periodistas del Post no deberían aceptar o ubicar símbolos, etiquetas o regalos virtuales de causas políticas o partidistas en páginas o sitios, y deberían monitorear la información publicada en sus propios perfiles personales por aquellos con quien están asociados online para que sea apropiada... (ASNE, 2011: 44)

El 'The New York Times' es un medio de gran referencia para los periodista y los ciberperiodistas, siempre a la vanguardia y sobre todo ante el auge de las redes sociales y la inmersión que se tiene. En este primer apartado se busca que el ciberperiodista reflexione sobre donde estamos, finalmente las redes sociales son un espacio en donde pareciera que nos podremos liberar, sin embargo siempre deberemos tener precauciones de ello.

126. Las páginas Web y los Web Logs (los diarios personales on line conocidos como blogs) presentan oportunidades imaginativas para la expresión personal y el excitante nuevo periodismo. Cuando son creados por nuestro personal o publicados en nuestros sitios web, también requieren precauciones, magnificadas por el ilimitado alcance de la Web. (ASNE, 2011: 40)

Sin duda alguna, los blogs en internet se presentan, para cualquier persona, como una gran oportunidad que permite expresar ideas y opiniones libremente respecto de cualquier tema. Sin embargo, para los ciberperiodistas el hacer uso de estos espacios conlleva un esfuerzo extra, ya que debe mantener un perfil personal definido que no comprometa su quehacer profesional o la línea editorial del medio en que desempeñe su actividad.

127. Los diarios personales que aparecen en nuestro sitio web oficial están sujetos a los estándares de imparcialidad, gusto y legalidad de la sala de redacción. Nada puede ser publicado bajo el nombre de nuestra compañía o cualquiera de nuestras 
unidades a menos que haya pasado a través del proceso de edición o moderación. (ASNE, 2011: 40)

Ante el surgimiento de estos espacios de publicación o expresión libre, como son los blogs, mantener la separación de los blogs personales de los ciberperiodistas y de contenidos publicados para un cibermedio, requiere un esfuerzo en conjunto, para ello, los cibermedios también se convierten en observadores, con la finalidad de resguardar su línea editorial.

128. Si un miembro del personal publica una página web o blog en un sitio fuera del control de nuestra compañía, este tiene el deber de asegurarse de que el contenido es solo eso: personal. Los miembros de personal que escriben blogs deberían generalmente evitar temas que cubren profesionalmente; fallar en hacerlo invitaría a una confusión de roles. Ninguna actividad personal web debería implicar la participación o el aval de Times Company o cualquiera de sus unidades. Nadie puede publicar texto, audio o video creado para la unidad de Times Company sin obtener el permiso apropiado. (ASNE, 2011: 40)

Los blogs, de alguna manera, deberán representar para los ciberperiodistas un espacio de esparcimiento, de liberación, en el cual únicamente

podrán plasmar sus intereses personales o hobbies, al realizarlo de esta manera, refrendan el compromiso que tienen con el cibermedio para el cual laboran y su ética profesional al mantener separados los ámbitos.

129. Dada la facilidad de búsqueda en la Web, incluso un diario privado de un miembro del personal es probable que llegue a estar asociado en la mente de la audiencia con la reputación de la compañía. Así, los blogs y las páginas web creadas fuera de nuestras instalaciones deben, no obstante, tener tono moderado, reflejar gusto, decencia y respecto por la dignidad y privacidad de otros.

También este cibermedio destaca la diferencia entre un blog personal el cual no debe estar correlacionado con el tipo de publicidad que se recibe directamente en el cibermedio. Se trabaja para una empresa periodística, en la cual se tiene que aplicar lo que es popular para los que nos dedicamos al periodismo que es la Cláusula de Conciencia.

131. La página web o el blog de un miembro del personal debe producirse independientemente. Debe estar libre de apoyo de publicidad o patrocinio de individuos $\mathrm{u}$ organizaciones cuya cobertura el miembro del personal probablemente haga, prepare o supervise durante sus horas de trabajo. (ASNE, 2011: 40).

\section{Resultados del Análisis de Contenido}

Como resultado del análisis de contenido ente lo que en la vida activa de las redes sociales hace el ciberperiodista y los lineamientos propuestos por los diversos cibermedios se presentan los siguientes resultados. No se verifican las informaciones, uno de los principios básicos del quehacer periodístico. Se presentan fallecimientos, destituciones, informaciones equivocadas sólo porque ese contenido ha sido manejado por un grupo numeroso de seres humanos a través de sus redes sociales. Aquí se aplica el principio democrático: "la mayoría de la gente no siempre tiene la razón”.

No se cotejan las fuentes primeras de donde proviene la información, en el periodismo sigue prevaleciendo la idea de que si está en Internet la información es correcta cuando la realidad es al contrario, es decir, la mayoría de los contenidos de Internet es falsa, tan es así que en espacios como Wikipedia se puede incluir demasiada información incorrecta.

También se observa en numerosas ocasiones el "corta y pega" en versión on line: periodistas y medios que se sirven de información obtenida en redes sociales sin citar la fuente o sin respetar los derechos de autor. Por ello, se compararon 50 redes sociales, como Twitter y Facebook de periodistas de cibermedios de Europa y Estados Unidos, frente a los de América Latina. Es importante precisar que las condiciones de trabajo y 
democráticas son distintas en América Latina, con respecto a Europa y Estados Unidos.

\section{Gráfico 2: Congruencia entre los principios} éticos del uso de las redes sociales y los contenidos

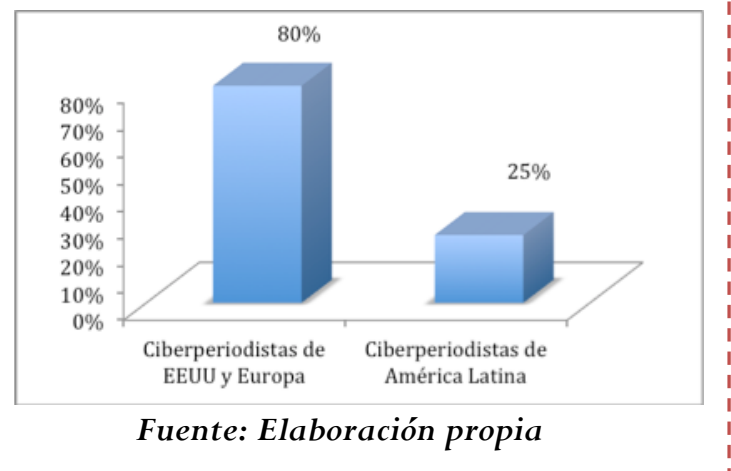

América Latina es una zona donde los medios analógicos, en su mayoría, no cuentan con Manuales de Estilo y de Ética; de hecho, la figura del Defensor del Lector, del Radioescucha o del Televidente no existe. Esto lamentablemente se ha trasladado a los cibermedios, sobre todo cuando en la mayoría de los casos fue un cambio de un medio analógico a uno digital.

Gráfico 3: Relación profesional con los usuarios a través de las redes sociales

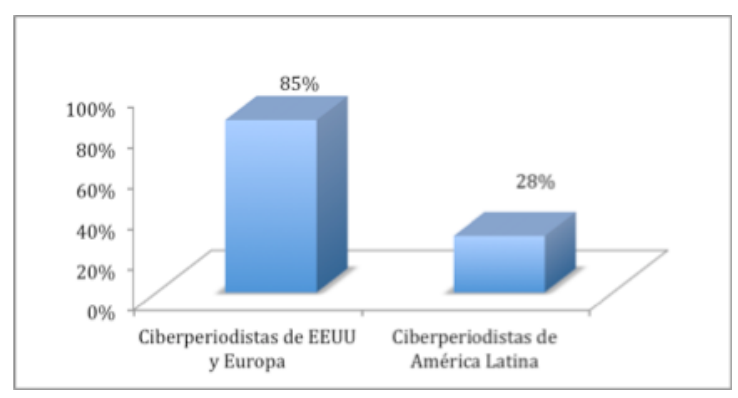

Fuente: Elaboración propia

El ciberperiodista de América Latina tiende a tener una relación cercana y personal, además de formar su identidad y su autoestima a partir de las redes sociales. Esto significa que la relación no es profesional y del ámbito laboral se pasa al privado. Aquí es importante recordar algo que pareciera muy extremo pero real que menciona 'The Washington
Post': Todos los periodistas del medio renuncian a algunos de los privilegios personales de los ciudadanos.

Gráfico 4: Publicación de noticias en la página y después en su red social

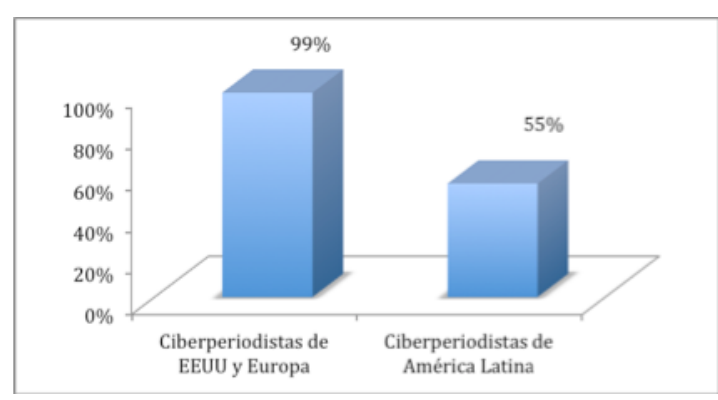

Fuente: Elaboración propia

Existe un imaginario del ciberperiodista de América Latina el cual considera que publicarlo en su red social le permite una ventaja.

Gráfico 5: Evitar conflicto de intereses ideológicos

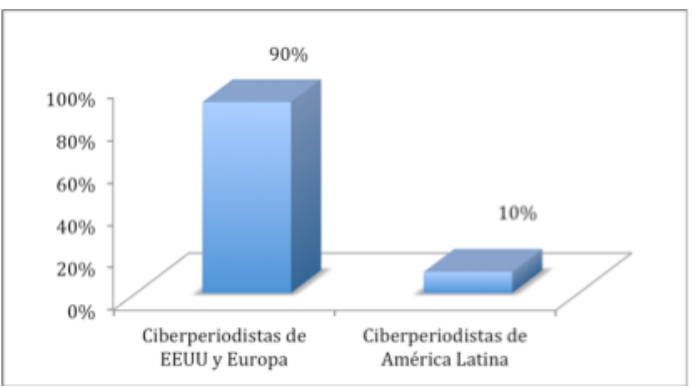

Fuente: Elaboración propia

Lamentablemente en este aspecto en América Latina se presenta una realidad, no existe una postura explícita de la ideología, como consecuencia, los reporteros y cibereporteros trabajan, en su mayoría, con intereses diferentes que van más hacia cuestiones económicas y de poder. 


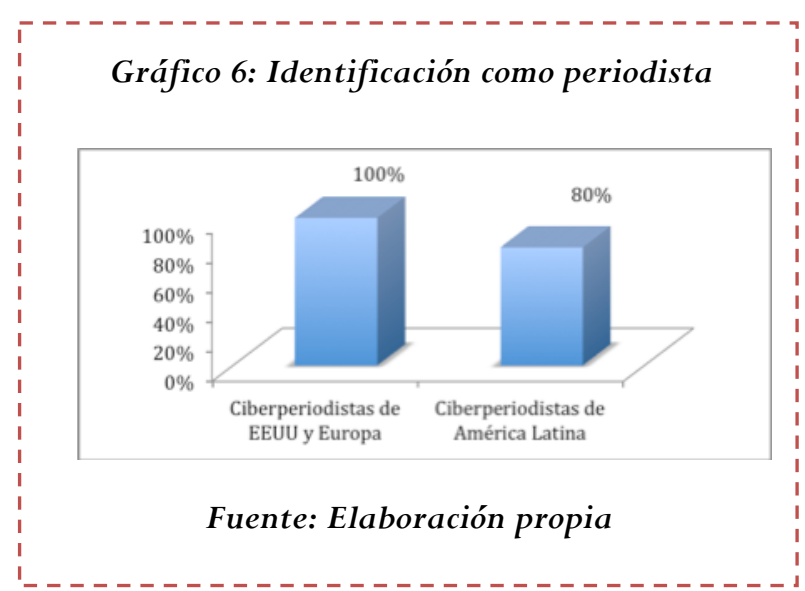

En esta variable, existe una responsabilidad de la identificación en el rol de ciberperiodista, esto significa que la persona que establece una relación de "amistad" lo hace con plena conciencia de con quien se está comunicando.

\section{Conclusiones}

Las redes sociales han emergido de una manera significativa, por ello se han podido abrir espacios en las salas de la ciberedacción como del monitorista, que es el asistente que monitorea una noticia o una información en las redes o en las bases de datos. Puede ser monitorista de: radio, prensa, televisión, de la web, de las redes sociales.

También se ubica al Director o responsable de Medios Sociales quien se encarga de los contenidos y del desarrollo de las redes sociales, ello con la finalidad de incorporar más usuarios a los espacios sociales de los medios. El ciberperiodista debe adelantarse a las necesidades del usuario, explotar los foros de discusión, las redes sociales, el chat y la posibilidad del correo electrónico para satisfacer esa demanda. Quien cumpla este cometido se adecuará a los nuevos tiempos.

Las redes sociales permiten a los ciberperiodistas y a los cibermedios interactuar de manera instantánea con otra persona o grupos sociales a través de la red. Las redes sociales son muy aplicables al trabajo de la ciberedacción para la búsqueda de información reciente.

El uso de las redes sociales y el empleo de ciertas herramientas informativas y dispositivos tecnológicos permite la participación ciudadana y el público se convierte en emisor de los mensajes, ambas partes deben estar conscientes de su posición y más el ciberperiodista porque de él depende la confirmación de los contenidos.
La mayoría de los medios informativos cuentan con redes sociales en las que divulgan los titulares de sus publicaciones, además permiten a cualquier usuario utilizar las redes sociales para compartir ciberinformaciones. En este caso no hay mayor problema, sin embargo estas redes deben estar supeditadas al manejo del cibermedio.

Recordemos aquí el juramento de la escuela más antigua de formación periodística en México, la Escuela de Periodismo Carlos Septién García:

Estoy consciente de que el periodismo, como forma social de la verdad, no se explica más que en su dimensión de hacer cada día más libres a los hombres. Entiendo mi responsabilidad ante este hecho, pues de no emplear la verdad en beneficio de la libertad social, me estaré haciendo cómplice, en consecuencia, de quienes se empeñan en manipular los hechos para esclavizar al hombre. ${ }^{1}$

El ciberperiodista debe de estar formado en este ámbito de las redes sociales, su expresión en los espacios digitales se convierte en una extensión de su quehacer profesional. Como lo mencionan en el emblemático 'The Washington Post', todos los periodistas renuncian a algunos de los privilegios personales de los ciudadanos. Los profesionales del periódico deben admitir que el contenido asociado a ellos en una red social es, a efectos prácticos, el equivalente de lo que aparece debajo de los

\footnotetext{
1 Juramento del Licenciado en Periodismo de la Escuela de Periodismo Carlos Septién García.
} 
subtítulos que aparecen en el periódico o en el sitio web.

La importancia de los cibermedios radica en el prestigio que tienen. En la confiabilidad que el usuario deposita en ellos. El cibernauta no puede consultar la totalidad de páginas web, ni tampoco puede confiar en la veracidad de la información que proporcionan. Los medios de comunicación ya conocidos son una fuente fidedigna, más que el resto de las páginas, todavía hoy en día no se puede confiar en la integridad de la información si no es en los nombres de marca.

Sólo los medios de prestigio cuentan con la imagen para su credibilidad (los que ya existían y eran respetados por el ejercicio del periodismo). Quienes somos amantes de la precisión en la información periodística los blogs y las redes sociales (todas, de hecho cada quien tienen una red social) no han sustituido lo que el periodismo serio y experto hace en todo esto y son los nombres de marca quienes obtienen la confianza del usuario.
Los espacios periodísticos tradicionales tienen la confianza de los usuarios. En las redes sociales nos podemos informar de lo que sucede tal vez de manera más inmediata, pero dudaremos, serán los ciberespacios quienes presentan la confiabilidad de lo que sucede. De hecho los medios más desarrollados tienen sus propias redes sociales, sin embargo cuando hay una información la comprueban antes de presentarla en el cibermedio. En la actualidad éste supera la credibilidad de la red o redes sociales del medio periodístico.

Hay que tener mucho cuidado de no convertirse en cómplices de la propagación de rumores tan comunes en sitios de Internet como en redes sociales. La clave del periodismo fue, es y será, la verificación. Al ciberciudadano que frecuentemente confunde su papel no se le exige esto, pero al ciberperiodista por supuesto que sí. Todos podemos recomendar una medicina, pero no seremos doctores, todos podemos emitir información en Internet, pero no será información periodística.

\section{Referencias}

- Agencia EFE (2011). Guía para empleados de EFE en redes sociales. España.

- American Society of News Editors (ASNE) (2011). Mejores Prácticas para Medios Sociales. Guías Útiles para las Organizaciones Periodísticas. Estados Unidos.

- Asociación de la Prensa Uruguaya (2012). Código de Ética Periodística. Uruguay.

- Conjunto de Guías Éticas para Hacer Periodismo en la Web (2011). Estados Unidos: Ed.

Knight Center.

- Díaz, Javier y Meso Ayerdi, Koldo (1999). Periodismo en Internet. Bilbao: Servicio Editorial de la Universidad del País Vasco.

- El País (2005). Libro de Estilo. España: Ed. El País.

- Gómez Aguilar, Marisol; Roses, Sergio y Farias Batlle, Pedro (2013). Las redes sociales profesionales en el sector periodístico. Nuevas herramientas para nuevos periodistas: El caso de LinkedIn, en Actas-V Congreso Internacional Latina de
Comunicación. España: Ed. Universidad de la Laguna.

- López, José (2007). El ciberperiodismo cultiva sus sueños de identidad. España en Ámbitos, No. 13-14.

- Llano Aristizábal, Sergicio (2005). Hipermedia e interactividad en el periodismo digital. Argentina en Palabra Clave, No. 12.

- Manual de Estilo Proceso (2009). México: Ed. Grijalbo.

- Martínez Albertos, José Luis (1997). El Ocaso del Periodismo. España: Ed. CIMS.

- Martínez, Omar Raúl. Repensar el Periodismo. Ed. Universidad Autónoma Metropolitana, México, 2011.

- Molina, Pedro (2008). Ciberperiodismo e interactividad: entre la participación y la apariencia. Revista Análisis, No 36.

- Navarro Zamora, Lizy (2012). Elementos de Ciberperiodismo. Ed. Fundación Manuel Buendía. 
- Urdaneta, Joyceleine (2007): Redacción en cibermedios para comunicadores en formación. México: En Razón y Palabra, Vol. 12 .

\section{Forma de Citación}

NAVARRO ZAMORA, Lizy: Principios Éticos para los Ciberperiodistas en el Manejo de las Redes Sociales. Revista Communication Papers, $\mathrm{N}^{\circ}$ 7, páginas 109 a 123. Departamento de Filología y Comunicación de la Universidad de Girona. Recuperado el _ de_ de 2 de: http://www.communicationpapers.es 